\title{
A geodynamic and mineral physics model of a solid-state ultralow-velocity zone
}

\author{
Dan J. Bower ${ }^{\mathrm{a}, \mathrm{b}}$, June K. Wicks ${ }^{\mathrm{b}}$, Michael Gurnis ${ }^{\mathrm{a}, \mathrm{b}}$, Jennifer M. Jackson ${ }^{\mathrm{a}, \mathrm{b}}$ \\ ${ }^{a}$ Seismological Laboratory, California Institute of Technology, Pasadena, California, USA \\ ${ }^{b}$ Division of Geological and Planetary Sciences, California Institute of Technology, \\ Pasadena, California, USA
}

\begin{abstract}
Recent results (Wicks et al., 2010) suggest that a mixture of iron-enriched $(\mathrm{Mg}, \mathrm{Fe}) \mathrm{O}$ and ambient mantle is consistent with wavespeed reductions and density increases inferred for ultralow-velocity zones (ULVZs). We explore this hypothesis by simulating convection to deduce the stability and morphology of such chemically-distinct structures. The buoyancy number, or chemical density anomaly, largely dictates ULVZ shape, and the prescribed initial thickness (proxy for volume) of the chemically-distinct layer controls its size. We synthesize our dynamic results with a Voigt-Reuss-Hill mixing model to provide insight into the inherent seismic tradeoff between ULVZ thickness and wavespeed reduction. Seismic data are compatible with a solidstate origin for ULVZs, and a suite of these structures may scatter seismic energy to produce broadband PKP precursors.
\end{abstract}

Keywords: ultralow-velocity zone, core-mantle boundary, mantle convection, PKP waves, (Mg,Fe)O

\section{Introduction}

The large chemical, density, and dynamical contrasts associated with the juxtaposition of liquid iron-dominant alloy and solid silicates at the coremantle boundary (CMB) are associated with a rich range of complex seismological features. Seismic heterogeneity at this boundary includes small patches of anomalously low sound velocities, called ultralow-velocity zones

Email address: danb@gps.caltech.edu (Dan J. Bower) 
(ULVZs). Their small size (5 to $40 \mathrm{~km}$ thick) (e.g., Garnero and Helmberger, $1996)$ and depth $(>2800 \mathrm{~km})$ present unique challenges for seismic characterization.

ULVZs were first noted with teleseismic SPdKS phase diffracting along the CMB to determine the P-wave velocity at the base of the mantle beneath the central Pacific (e.g., Garnero et al., 1993; Garnero and Helmberger, 1995, 1996; Helmberger et al., 1996). The compressional wavespeed decreases by 5 to $10 \%$ over a depth of 5 to $40 \mathrm{~km}$ above the CMB, consistent with PcP precursors (e.g., Mori and Helmberger, 1995; Revenaugh and Meyer, 1997; Hutko et al., 2009). In other locations, ULVZs are seismically absent or below the detection threshold, such as the North Pacific (Rost et al., 2010b), which may imply they are not globally ubiquitous (see Thorne and Garnero, 2004). ULVZs have been correlated with the location of hotspots (Williams et al., 1998) and tentatively to the edges of large low shear velocity provinces (e.g., Lay et al., 2006). Recent thermochemical convection calculations lend support to these spatial correlations (McNamara et al., 2010).

Precursors and postcursors to the converted core-reflected phase ScP can potentially constrain the $\mathrm{P}$ and $\mathrm{S}$ wavespeed, thickness, and density of ULVZs (e.g., Garnero and Vidale, 1999; Reasoner and Revenaugh, 2000). Based on this approach, analyses using small-aperature and short-period arrays have elucidated the structure between Tonga-Fiji and Australia at high resolution (Rost and Revenaugh, 2003; Rost et al., 2005, 2006; Idehara et al., 2007; Rost et al., 2010a). These studies report $\mathrm{P}$ and $\mathrm{S}$ wavespeed reductions of $\approx 8 \%$ and $\approx 24 \%$ respectively, a thickness of about $10 \mathrm{~km}$, and a density increase of around $10 \%$.

All of these studies characterize structure by a 1-D model. Although quasi-1D models utilize different structures for the source and receiver paths (e.g., Garnero and Helmberger, 1996; Helmberger et al., 1996), only a few 2-D models have been reported. Probing the CMB beneath the southwest Pacific, Wen and Helmberger (1998b) model SKS-SPdKS observations with Gaussian-shaped ULVZs of approximately $40 \mathrm{~km}$ in height, 250 to $400 \mathrm{~km}$ lateral extent, and a P-wavespeed drop of about 10\%. PKP precursors suggest that these larger structures are composed of smaller undulations (Wen and Helmberger, 1998a). A concave-down upper interface is necessary to model structures beneath Africa and the eastern Atlantic (Helmberger et al., 2000). In both 1-D and 2-D models there are tradeoffs between the height and velocity decrease of ULVZs (e.g., Garnero and Helmberger, 1998; Wen and Helmberger, 1998b). 
A partial melt origin for the ULVZs predicts a $\mathrm{P}$ to $\mathrm{S}$ wavespeed reduction of about 1:3 (Williams and Garnero, 1996; Berryman, 2000; Hier-Majumder, 2008). In this model, the velocities of the average assemblage are decreased by melt formed either by fluid reaction products of Fe liquid with silicate mantle or by partial melting of Fe-rich mantle. The hypothesis is consistent with the correlation between ULVZs and hot spots (Williams et al., 1998) and the broad agreement with $\mathrm{P}$ to $\mathrm{S}$ velocity reductions determined from core-reflected phases. Early dynamical calculations question the ability to produce a dense and non-percolating melt phase in the deep Earth (Hernlund and Tackley, 2007). However, the stirring of ULVZs by the larger-scale convective motions of the mantle can potentially maintain a partially molten region (Hernlund and Jellinek, 2010). Partial melt may also be trapped within ULVZs because of textural changes (e.g., Rost et al., 2005, 2006), but theoretical and experimental justifications are incomplete, particularly at the temperatures and pressures of the CMB region.

Iron enrichment of solid phases, specifically the increase in $\mathrm{Fe} /(\mathrm{Fe}+\mathrm{Mg})$ ratio, can simultaneously increase density and reduce compressional and shear velocity (e.g., Karato and Karki, 2001). This partly inspired the notion of solid, iron-rich ULVZs, such as a metal-bearing layer (Knittle and Jeanloz, 1991; Manga and Jeanloz, 1996), subducted banded iron formations (Dobson and Brodholt, 2005), or iron-enriched post-perovskite (Mao et al., 2006; Stackhouse and Brodholt, 2008). Iron-rich systems are typically denser than the surrounding mantle, which is required to explain the locations of ULVZs at the base of the mantle.

Recent results show that the sound velocities of a solid iron-enriched (Mg,Fe)O at CMB pressures are low enough, such that only a volumetrically small amount $(\sim 10-20 \%)$ mixed with coexisting silicates are needed to explain ULVZs (Wicks et al., 2010). We are motivated to generate a numerical convection model of a thin, iron-enriched ( $\mathrm{Mg}, \mathrm{Fe}) \mathrm{O}$-containing layer interacting with the lowermost thermal boundary layer. Mantle convection thickens (thins) a dense layer beneath upwellings (downwellings) and controls its spatial distribution (Davies and Gurnis, 1986). A persistent stable layer has a density contrast of a few percent (e.g., Garnero and McNamara, 2008) and may convect internally (Hansen and Yuen, 1988). We explore whether these characteristics are manifested in this iron-enriched $(\mathrm{Mg}, \mathrm{Fe}) \mathrm{O}-$ containing layer. We determine the steady-state morphology of such a layer and develop an integrated and self-consistent ULVZ model which uses constraints from geodynamics and mineral physics and is consistent with seismic 
data.

\section{Numerical Models}

\subsection{Equations and solution methods}

We apply the Boussinesq approximation to model thermochemical convection using CitcomS (Zhong et al., 2000; Tan et al., 2007) because the pressure range of our domain is small and energy dissipation is negligible with a greatly reduced thermal expansion coefficient at high pressure. The equation for the conservation of mass for an incompressible fluid is:

$$
\nabla \cdot \mathbf{u}=0
$$

where $\mathbf{u}$ is velocity. The non-dimensional momentum equation is:

$$
-\nabla P+\nabla \cdot(\eta \underline{\underline{\underline{\epsilon}}})=(R b C-R a T) \hat{\mathbf{r}}
$$

where $P$ is the dynamic pressure, $\eta$ is the viscosity, $\underline{\underline{\epsilon}}$ is the deviatoric strain rate, $R a$ is the thermal Rayleigh number, $T$ is temperature (nondimensionally ranging from 0 to 1$), R b$ is the chemical Rayleigh number, and $\hat{\mathbf{r}}$ is the radial unit vector. Composition, $C$, ranging from 0 to 1 , encompasses two chemical components. The first component $(C=0)$ is ambient mantle, the second $(C=1)$ is a two-phase mix containing iron-enriched $(\mathrm{Mg}, \mathrm{Fe}) \mathrm{O}$ that constitutes the distinct chemistry of the ULVZ. We equivalently refer to the latter component as the chemical, or ( $\mathrm{Mg}, \mathrm{Fe}) \mathrm{O}$-containing, component.

The Rayleigh numbers are defined as:

$$
\begin{aligned}
R a & =\frac{\rho \alpha \Delta T D^{3} g}{\eta_{0} \kappa} \\
R b & =\frac{\Delta \rho_{c h} D^{3} g}{\eta_{0} \kappa}
\end{aligned}
$$

where the parameters and their values are provided in Table 1.

A useful non-dimensional parameter is the buoyancy number, $B$, which describes the chemical density anomaly normalized by the maximum thermal density anomaly, or equivalently the ratio of chemical to thermal buoyancy:

$$
B=\frac{R b}{R a}=\frac{\Delta \rho_{c h}}{\rho \alpha \Delta T}
$$


The quantity of heat-producing elements in the lower mantle and the dynamic implications for small-scale structures such as ULVZs remain uncertain. For simplicity, we solve the non-dimensional energy equation for temperature without an internal heat source:

$$
\frac{\partial T}{\partial t}+(\mathbf{u} \cdot \nabla) T=\nabla^{2} T
$$

where $t$ is time.

The equation for chemical advection is:

$$
\frac{\partial C}{\partial t}+(\mathbf{u} \cdot \nabla) C=0
$$

We represent the ULVZ component by a set of tracer particles (initially about $100 /$ cell) that are advected using a predictor-corrector scheme (McNamara and Zhong, 2004). The volume fraction of ULVZ material is proportional to the absolute local concentration of tracers with a truncation applied to prevent unphysically large values (see Tackley and King, 2003, the truncated absolute method). In comparison to the ratio method (Tackley and King, 2003), this technique provides greater computational speed because fewer total tracers are required. Although the number of tracers per cell is greater for the absolute method to achieve the same resolution, a large volume fraction of ambient material in our models is devoid of tracers. By contrast, the ratio method requires tracers to fill the space of the entire domain.

\subsection{Domain and rheology}

We solve for the flow within a small region near the CMB in a cylindrical geometry. Our domain $(513 \times 145$ nodes $)$ spans approximately $23^{\circ}$ with a height of 488 kilometers above the CMB. The radial resolution is $2 \mathrm{~km}$ in the lowermost $256 \mathrm{~km}$ of the domain. Above $256 \mathrm{~km}$ the grid spacing increases incrementally by $2 \mathrm{~km}$ to a maximum of $20 \mathrm{~km}$.

Non-dimensional viscosity (normalized by $\eta_{0}$, see Table 1 ) follows a linearized Arrhenius law; recalling that $T$ is non-dimensional temperature:

$$
\eta(T)=\exp \left(-\ln \left(10^{q}\right) T\right)
$$

where $q$ specifies the order of magnitude of viscosity variation within the domain (see Table 1) and is largely restricted by numerical considerations. The stability of the lower thermal boundary layer is strongly dependent on 
$q$ (e.g., Yuen and Peltier, 1980; Loper and Eltayeb, 1986). The background viscosity modulates the critical size that an instability must attain before a diapir can detach from the thermal boundary layer (e.g., Olson et al., 1987). Therefore, the reference viscosity $\eta_{0}$ (see Table 1 ) is representative of the unperturbed ambient mantle beyond the influence of the thermal boundary layer.

\subsection{Boundary and initial conditions}

The comparatively large lateral extent of the domain limits the sensitivity of the solution to the insulating sidewalls. The bottom boundary (CMB) is isothermal and free slip. We apply two different top boundary conditions. An isothermal and free slip condition (impermeable) excessively constrains flow and retards upwellings. In contrast, a boundary prescribed by zero normal stress, zero horizontal velocities, and zero heat flux (permeable) (e.g., Tan et al., 2002) lessens resistance so that instability growth accelerates. The impermeable and permeable conditions effectively bound the characteristic dynamic timescales that we expect for an evolving thin boundary at the base of a thick domain (Olson et al., 1987).

Ambient deep mantle is prescribed at zero (non-dimensional) temperature, and the isothermal lower boundary is set to unity. The temperature scaling is given in Table 1 . We apply a half-space cooling model with an age of 25 Myr to generate a lower thermal boundary layer with a thickness of $\approx 66 \mathrm{~km}$. We place a thin layer of the chemical component at the base within the thermal boundary layer. Both the buoyancy number $(B)$ and initial thickness $\left(d_{c h}\right)$ are free parameters (see Table 1$)$. We explore cases where $d_{c h}$ ranges from $32 \mathrm{~km}$ to $2 \mathrm{~km}$, which is between 2 and 33 times smaller than the initial thermal thickness. This is reasonable given the expected thickness $(5-40 \mathrm{~km})$ of ULVZs.

We allow the chemical layer to be swept into one coherent structure by applying a half sinusoidal perturbation to the temperature field (initially of non-dimensional magnitude of 0.05 ) both radially and laterally. This permits the outcome of the different numerical experiments to be compared more readily. The size of our domain is carefully specified to focus on individual ULVZ structures and is not designed (nor suitable) to analyze the spatial distribution of many piles. Physically, our chosen initial perturbation is akin to an upwelling on the CMB caused by the (symmetric) downwelling of ambient material on either side. 


\section{Results}

\subsection{Transient period}

We refer to the initial stage of the model evolution as the transient period. Although we are primarily concerned with the long-term stability and morphology of ULVZs, during this time we make several observations. We overview the evolution of four extreme cases (all impermeable), given by the following parameter values: $\left(B=0.5, d_{c h}=16 \mathrm{~km}\right),\left(B=4, d_{c h}=16 \mathrm{~km}\right)$, $\left(B=0.5, d_{c h}=8 \mathrm{~km}\right)$, and $\left(B=4, d_{c h}=8 \mathrm{~km}\right)$.

For $\left(B=0.5, d_{c h}=16 \mathrm{~km}\right)$ (Fig. 1$)$, the thermal boundary layer develops two dominant instabilities within the chemical layer (Fig. 1A) that are ultimately overwhelmed by the imposed long-wavelength perturbation (Fig. 1B). During this period, the chemical layer develops significant relief caused by the developing plumes, until the plumes merge and a large volume fraction of the layer is expelled from the CMB region (Fig. 1C). The buoyancy of the plume generates viscous stresses that support the relief of the remaining chemical material anchored at the CMB. Stresses reduce as the plume ascends away from the lower boundary and the convection approaches a steady-state, causing a marginal reduction in relief.

The evolution for the case with the same buoyancy number, but a thinner layer $\left(B=0.5, d_{c h}=8 \mathrm{~km}\right)$ is similar, but the dynamic timescale is reduced by several tens of million years. This occurs for all cases with a thinner layer, because less thermal buoyancy (less thickening of the boundary layer) is necessary to overcome the intrinsic density increase of the chemical layer.

For the cases with a large chemical density anomaly, $\left(B=4, d_{c h}=16 \mathrm{~km}\right)$ and $\left(B=4, d_{c h}=8 \mathrm{~km}\right)$, a single plume forms that marginally deflects the layer upward as it leaves the CMB region. The influence of the buoyant plume is lessened as it approaches the top of the domain, which causes the layer to flatten slightly. The large chemical density anomaly prevents substantial topography from forming on the interface.

\subsection{Steady-state}

After the initial transient period, the low effective Rayleigh number ensures that almost all models reach a steady-state, defined by $<1 \mathrm{~km}$ fluctuations (standard deviation) in structure height. We can thus determine several time-independent characteristics. We record the layer dimensions for the impermeable cases during a steady-state time window defined after the plume reaches the top of the domain but before the downwellings exert 
sufficient stress to further deform the chemical layer. The permeable cases are unaffected by return flow because material is allowed to escape from the domain.

Five impermeable cases are time-dependent because of an oscillatory flow driven by a pulsating plume that marginally raises and flattens the chemical structure. We compute the standard deviation of the maximum height $(\mathrm{km})$, $h_{s d}$, during a stationary time window: $\left(B=0.5, d_{c h}=2 \mathrm{~km}\right): h_{s d}=5.8 \mathrm{~km}$, $\left(B=0.5, d_{c h}=4 \mathrm{~km}\right): h_{s d}=2.6 \mathrm{~km},\left(B=0.75, d_{c h}=2 \mathrm{~km}\right): h_{s d}=1.9$ $\mathrm{km},\left(B=0.75, d_{c h}=4 \mathrm{~km}\right): h_{s d}=1.1 \mathrm{~km}$ and $\left(B=1, d_{c h}=2 \mathrm{~km}\right)$ : $h_{s d}=1.5 \mathrm{~km}$. These models are characterized by a low buoyancy number and low initial layer thickness such that the buoyancy of the chemical layer is insufficient to stabilize the flow. We time-average these cases to deduce the stationary steady-state behavior.

Fig. 2 depicts all of our parameter space. The relief is defined as the difference between the maximum and minimum height of the structures above the CMB over the lengthscale of the domain $(\sim 1400 \mathrm{~km})$ at steady-state. This metric becomes less appropriate for cases where the ULVZ spreads over a distance greater than $1400 \mathrm{~km}$, thus creating a ubiquitous layer with a much reduced relief even though a potentially voluminous layer exists. Although this may not occur within a larger model domain, a thick continuous layer does not satisfy the small-scale localized nature of the ULVZs. The two largest initial chemical layer thicknesses, $d_{c h}=32 \mathrm{~km}$ and $d_{c h}=24 \mathrm{~km}$, generally produce thick ubiquitous layers, or structures with reliefs that are too large to reconcile with seismic observations (i.e. $\gtrsim 100 \mathrm{~km}$ ). We therefore do not discuss these results further.

A certain volume of residual material is necessary to generate structural reliefs within the seismic estimates of 5-40 km. In these models, this can be achieved by either entraining a large amount of material from a thicker chemical layer e.g. $\left(B=0.5, d_{c h}=16 \mathrm{~km}\right)$, or by starting with less material e.g. $\left(B=0.75, d_{c h}=4 \mathrm{~km}\right)$.

We plot the steady-state morphologies for the impermeable and permeable cases in Figs. 3, 4, and 5. Although the dynamic timescales are affected by the top boundary condition, the long-term evolution of the structures is comparable. Models with low $B$ exhibit triangular morphologies and these shapes progressively flatten as $B$ is increased, with the upper interface becoming more rounded. The morphologies are relatively insensitive to $d_{c h}$, although for reduced $d_{c h}$ the structures exhibit slightly flatter tops (e.g., Fig. 3) 
Entrainment modulates the quantity of material available to form the structures for $B \lesssim 0.75$. For $d_{c h} \geq 8 \mathrm{~km}$ a large volume fraction of the chemical layer is entrained when $B=0.5$, which explains the substantially reduced size of the triangular ULVZs. This effect is accentuated for the impermeable cases because of increased viscous stresses. Entrainment is most effective at early model time because viscosities and density differences are comparable (e.g., Sleep, 1988). For this reason, the thinnest initial layer is less affected because it is deeply embedded in the hottest, least viscous part of the domain. Lin and van Keken (2006) describe the entrainment as endmember regimes, which can conveniently be applied to our models. In their regime $I$, the plume head is formed by ambient material above the CMB, and no chemically-distinct material is entrained. This occurs for $B \gtrsim 0.75$ in our models. $B \lesssim 0.75$ is characteristic of their regime III, particularly for $d_{c h} \geq 8 \mathrm{~km}$, because the dense component predominantly accumulates at the base of the plume with some entrainment by the plume head. In addition to this complex entrainment behavior, relief varies most greatly around $B=1$ because of the comparable thermal and chemical buoyancy (Fig. 3).

The half-widths of the structures vary in proportion to $B$ (Fig. 4). Since $d_{c h}$ limits the total volume of material available to form the ULVZ, the halfwidth also varies in proportion to $d_{c h}$. For $B \gtrsim 0.75$ the permeable cases produce structures that are slightly less flattened than the impermeable cases, with a subsequent reduction in half-width. The largest variations for both half-widths and relief occur for the thickest initial layer, $d_{c h}=16 \mathrm{~km}$. In Fig. 5 we show that the aspect ratio (relief/half-width) of the structures is strongly dependent on $B$ and only marginally dependent on $d_{c h}$.

\section{Discussion}

PKP precursors provide evidence for scatterers of varying lengthscales at the CMB (Cleary and Haddon, 1972). Our simulations generate structures of various shapes and sizes (e.g., Fig 3) which are comparable to the small-scale and large-scale features used to model broadband data (Wen and Helmberger, 1998a). This suggests that solid-state ULVZs are strong candidates for the origin of the scatterers, particularly if dynamic processes sweep together several ULVZs of differing lengthscales. Many of our dynamic structures also have concave-down upper surfaces that are akin to the 2-D Gaussian-shapes used to model seismic data (e.g., Wen and Helmberger, 1998a,b). A curved surface generates long-period PKP precursors by wide-angle reflection ( Wen 
and Helmberger, 1998a), reduces the amplitudes (relative to a 1-D model) of SKS-SPdKS phases, and produces strong precursors to ScP and ScS (Wen and Helmberger, 1998b). The sharp tops of ULVZs inferred seismically (e.g., Rost et al., 2005) motivated our a priori choice to define a pre-existing sharp boundary separating the chemical component from ambient mantle (e.g., Fig 6). If the iron-rich $(\mathrm{Mg}, \mathrm{Fe}) \mathrm{O}$-containing component is formed through a diffusive process, for example by reactions with the core, the interface is not as sharp (e.g., Kellogg and King, 1993).

Countercirculation is observed in all models, and two cases are shown in Fig. 6. Viscous coupling is energetically favorable because it minimizes viscous shear at the material interface (e.g., Richter and McKenzie, 1981). Similarly, in a series of laboratory tank experiments, Jellinek and Manga (2002) observe a preference for material to rise along the sloping interface between a low viscosity chemical layer and ambient material.

In Fig. 6A the ULVZ has sufficient thickness to greatly influence the thermal structure in the lowermost $90 \mathrm{~km}$, and the two-layer convective regime is clearly revealed by Profile II in Fig. 6C. Isotherms are deflected to lower pressure about the central upwelling, which will determine the stable phase assemblages and melt generation zones. Our solid-state model does not require partial melt to account for the dynamic or wavespeed character of ULVZs, but neither is it explicitly excluded. In this regard, partial melt may explain local variations in ULVZ structure, for example beneath the Philippine-Kalimantan region (Idehara et al., 2007).

For $B \gtrsim 2$, the amplitude of the steady-state perturbation of the chemical layer is much reduced, approximately $35 \mathrm{~km}$ in Fig. 6B. The velocity arrows indicate that this flow is generally sluggish with a recirculation of material accommodated by a low viscosity channel at the very base of the domain. Conduction is clearly the dominant heat transfer mechanism (Fig. 6D) and the extreme outcome for this regime is a ULVZ that is subcritical to convection. In this case the ULVZ would act like a 'hot plate' at the base of the mantle and simply offset the thermal boundary layer to marginally lower pressure.

Youngs and Houseman (2009) determine that half-width $\propto B^{0.38}$ and height $\propto B^{-0.39}$ based on calculations in a 3-D Cartesian geometry using an isoviscous fluid. In our models, however, we have a temperature-dependent viscosity that introduces a non-linearity which increases the complexity of the convection and questions the applicability of simple scaling relations that involve $B$. Given this caveat, we find that the exponent of $B$ for half-width 
ranges between 0.76 and 0.37 , and for the height ranges between -0.72 and -0.34 .

We now consider the uncertainties in our geodynamic modeling and their implications. The Rayleigh number affects the morphology of a chemical layer and its topography scales approximately in proportion to $R a^{-1 / 3}$ ( Tackley, 1998). We assume a thermal conductivity of around $6.6 \mathrm{~W} / \mathrm{m}-\mathrm{K}$ (e.g., de Koker, 2010) but larger values (around $28 \mathrm{~W} / \mathrm{m}-\mathrm{K}$ ) have been reported (Hofmeister, 2008). The scaling relation thus predicts that the topography of the chemical layer could be 1.6 times larger than our model predicts. Similarly, an upper bound for lower mantle viscosity is two orders of magnitude larger than our reference value (e.g., Ammann et al., 2010), which by itself could increase relief by a factor of 4.6. Both high thermal conductivity and lower mantle viscosity could collectively elevate the topography by 7.5 times, but mid-range estimates predict a more modest increase of a factor of 1.6.

Appropriate activation enthalpies for the deep Earth may induce an order of magnitude viscosity variation ( $q$ in equation 8 ) greater than 3 . For example, assuming a CMB temperature of $3700 \mathrm{~K}$, a low enthalpy of $500 \mathrm{~kJ} / \mathrm{mol}$ (Yamazaki and Karato, 2001) results in $q \sim 4$, and a higher estimate of 792 $\mathrm{kJ} / \mathrm{mol}$ (Ammann et al., 2009) leads to $q \sim 7$. When $q \gtrsim 3$, instabilities are initially confined to the boundary layer (Christensen, 1984). Further increasing $q$ reduces the onset time to instability, decreases the scale of flow, and intensifies the time dependence (Olson et al., 1987). This eventually leads to a broad-scale well-mixed upwelling with low viscosity (e.g., Christensen, 1984; Thompson and Tackley, 1998). Our models do not generate this type of instability because of the reduced viscosity contrast $(q=3)$ and the imposed long-wavelength thermal perturbation. We would expect such a plume to modify the quantity of residual material at the CMB, although this regime may not be applicable to ULVZs that are only around 2 orders of magnitude weaker than the ambient material (Hier-Majumder and Revenaugh, 2010).

To associate aggregate chemical density anomalies to P-wave velocity $\left(\mathrm{V}_{P}\right)$ and S-wave velocity $\left(\mathrm{V}_{S}\right)$ of the ULVZs we use a Voigt-Reuss-Hill (VRH) mixing model (see Watt et al., 1976). We estimate ULVZ properties as a mixture of a silicate component and a dense oxide, and density anomalies are generated by varying the fraction of oxide in the solution. In our first mixing model we assume a disequilibrium assemblage to avoid unnecessary speculation on lowermost mantle mineralogy, and focus on the combination of properties rather than specific stable coexisting phases. The composition and properties of the silicate component are not well constrained in a chemically- 
distinct ULVZ, so we use PREM as the model for its density and velocity. The dense oxide is assumed to be $\left(\mathrm{Mg}_{0.16} \mathrm{Fe}_{0.84}\right) \mathrm{O}$ magnesiow üstite $(\mathrm{Mw})$, as this is the only composition for which extremely low sound velocities have been measured at appropriate pressures (Wicks et al., 2010). We refer to this model as "Mw + PREM". Calculations are made at $121 \mathrm{GPa}$, the highest pressure reached in the experimental study, and our model is extrapolated to a high $(4700 \mathrm{~K})$ and low $(2700 \mathrm{~K})$ temperature estimate of the CMB. The temperature derivatives of velocity used are $\partial V_{P} / \partial T=-4.64 \times 10^{-4}$ $(\mathrm{km} / \mathrm{s}) \mathrm{K}^{-1}$ and $\partial V_{S} / \partial T=-3.85 \times 10^{-4}(\mathrm{~km} / \mathrm{s}) \mathrm{K}^{-1}$, measured on $\mathrm{MgO}$ using a multi-anvil apparatus up to $24 \mathrm{GPa}$ and $1650 \mathrm{~K}$ (Kono et al., 2010). The measured thermal expansion of FeO at $93 \mathrm{GPa}, \alpha=0.54 \times 10^{-5} \mathrm{~K}^{-1}$ (Seagle et al., 2008), is used to estimate the temperature dependent density of $\left(\mathrm{Mg}_{0.16} \mathrm{Fe}_{0.84}\right) \mathrm{O}$. Under these assumptions, our VRH mixing model produces a range of $\mathrm{V}_{P}$ and $\mathrm{V}_{S}$ for a given chemical density anomaly (Fig. 7A, B).

We also construct a second mixing model to consider the effects of Fepartitioning between magnesium silicate perovskite $(\mathrm{Pv})$ and $\mathrm{Mw}$ ("Mw + Pv"). Estimates for the Fe-partitioning between these phases approaching $\mathrm{CMB}$ conditions varies between $K_{D}^{\mathrm{Pv} / \mathrm{Mw}} \approx 0.42$ for pyrolitic composition (Murakami et al., 2005) and $K_{D}^{\mathrm{Pv} / \mathrm{Mw}} \approx 0.07$ for an Al-free system (e.g., Sakai et al., 2009; Auzende et al., 2008). Trends indicate that $K_{D}^{\mathrm{Pv} / \mathrm{Mw}}$ is likely lower at higher pressures and Fe-content, but it is not possible to reliably extrapolate from present datasets. This mixing model necessitates a small $K_{D}^{\mathrm{Pv} / \mathrm{Mw}}$ to produce an equilibrium phase assemblage with a bulk density comparable to PREM and thus density anomalies (equivalently $B$ ) that are contained within the range of this study. Assuming $\left(\mathrm{Mg}_{0.16} \mathrm{Fe}_{0.84}\right) \mathrm{O}$ as the oxide phase and with $K_{D}^{\mathrm{Pv} / \mathrm{Mw}}=0.07$ predicts a coexisting $\mathrm{Pv}$ of composition $\left(\mathrm{Mg}_{0.72} \mathrm{Fe}_{0.28}\right) \mathrm{SiO}_{3}$. Such high $\mathrm{Fe}$-contents may be unstable in both Mw (Dubrovinsky et al., 2000) and $\mathrm{Pv}$ (Mao et al., 2005), but other experimental results indicate otherwise (Tateno et al., 2007; Lin et al., 2003). Possible coexistence of post-perovskite in the presence of $\mathrm{Al}$ and Fe adds further complication (Andrault et al., 2010), so we extrapolate assuming a high $\mathrm{CMB}$ temperature estimate $\left(\mathrm{T}_{C M B}=4700 \mathrm{~K}\right)$ to promote $\mathrm{Pv}$ as the stable silicate phase. Although the presence of Al throughout the lower mantle may alter the partitioning behavior (e.g., Irifune, 1994) and select thermoelastic properties (e.g., Jackson et al., 2005), we focus on an Al-free system to simplify the results. The composition and properties of $\mathrm{Pv}$ are determined from a finite strain model ( $\mathrm{Li}$ and Zhang, 2005) where effects 
of Fe are neglected except for a correction to the density. In exploratory models we perturbed the bulk and shear moduli due to Fe-content (Kiefer et al., 2002) but discovered this had marginal impact. We select an adiabat foot temperature for $\mathrm{Pv}$ that reaches $4700 \mathrm{~K}$ at $121 \mathrm{GPa}$ and extrapolate the dense oxide to high temperature using the same procedure as previously described.

The chemical density anomalies of the mixing models can be directly associated with the buoyancy numbers used in the geodynamic calculations (Fig. 7C). Assuming a high $(1500 \mathrm{~K})$ and low $(500 \mathrm{~K})$ estimate for the temperature drop at the CMB, we can therefore predict a relationship between the wavespeed reduction and relief (thickness) of ULVZs. Our geodynamic models assume $\Delta T=1500 \mathrm{~K}$ (see Table 1), so we introduce an inconsistency by mapping the data using a reduced $\Delta T=500 \mathrm{~K}$, but the Rayleigh number is small (a factor 2-3 difference) and does not alter the dynamics significantly. Exploring the implications of a high and low temperature drop at the CMB adds to the predictive capabilities of our synthesized model. For visual clarity we now plot only the Hill bound, and compare to seismic data (Figs. 8 and 9). For example, in Fig. 8B, the "Mw + Pv" model at $4700 \mathrm{~K}$ $(\Delta T=500 \mathrm{~K})$ with relief of $95.7 \mathrm{~km}$ produces a $\mathrm{V}_{P}$ velocity reduction of $\sim 5 \%$ with $\sim 4$ vol. $\%$ of $\mathrm{Mw}$. In the same model, $\sim 9 \% \mathrm{Mw}$ produces a $\mathrm{V}_{P}$ reduction of $\sim 9 \%$, resulting in a relief of $27.5 \mathrm{~km}$.

A negative correlation between ULVZ thickness and wavespeed reduction is expected given the inherent tradeoff in modeling seismic data. This is more evident with $V_{P}$ (Fig. 8A) than $V_{S}$ (Fig. 9A). However, this difference may be due to sampling biases. To discern $V_{P}$ at the base of the mantle the original seismic studies utilize long-period data which is more sensitive to long wavelength structure. In contrast, shorter period reflected phases are commonly used to determine $V_{S}$ structure, and hence thin ULVZs are often detected. For both wavespeeds, a cluster of datapoints populate a broad range of wavespeed reductions for the thinnest ULVZs, implying substantial local variations.

The modeled $V_{P}$ and $V_{S}$ can reproduce the seismic observations for a reasonable range of expected temperatures and temperature drops in the CMB region. 2-D studies are denoted by filled symbols in Figs. 8A and 9A. As previously noted, the seismic data exhibits a broad scatter. Localized variations in ULVZ structure and material properties, caused by temperature or chemistry, may explain this spread. However, it is noteworthy that our synthesized model, which combines empirically determined wavespeeds with 
geodynamic simulations, is capable of explaining the current observations.

The PREM mixing model ("Mw + PREM") intrinsically overestimates the density and wavespeeds of the silicate component in the cases we explore here, because we do not explicitly model the silicate at high temperatures (Figs. 8 and 9). This model therefore underestimates wavespeed reductions and can be considered a lower bound. The Fe-partitioning model ("Mw + $\mathrm{Pv}$ ") provides insight into the importance of both Fe-content and temperature in modulating the physical properties and seismic characteristics of ULVZs. Since both $\mathrm{Mw}$ and $\mathrm{Pv}$ have high Fe-contents the compositional density of the assemblage is high relative to PREM and is therefore likely to form a flat layer. Higher temperatures, however, reduces total density whilst further reducing wavespeeds. At $T_{C M B}=4700 \mathrm{~K}$ the density of the silicate is sufficiently reduced that a large volume fraction of $\mathrm{Mw}$ (also of reduced density) is incorporated into the assemblage to obtain PREM-like densities. This allows large wavespeed reductions for relatively small density anomalies.

There are multiple avenues for future work. Limited constraints on the chemistry and properties of the ULVZ phases under appropriate conditions introduce uncertainties into our VRH mixing model to predict expected $V_{P}$, $V_{S}$, and density anomalies. A better constraint on the temperature and phase relations in $\mathrm{D}^{\prime \prime}$, coupled with sound velocity measurements of these phases at CMB conditions, would help to constrain the composition. Our geodynamic simulations assume a priori that there is an availability of $\mathrm{FeO}-$ enriched material at the base of the mantle to form ULVZs. It would therefore be useful to unravel the mechanism for creating an FeO-enriched layer to constrain its likely volume and iron content. Furthermore, our results are sensitive to the initial thickness (proxy for volume) of this layer.

\section{Summary and conclusions}

We explore the geodynamic implications of a solid iron-enriched $(\mathrm{Mg}, \mathrm{Fe}) \mathrm{O}$ layer for the origin of ULVZs. Our numerical simulations produce ULVZs with a sharp and concave-down seismic top, appropriate horizontal and vertical lengthscales and an intrinsic density increase. Models with similar features can explain the scattering origin of PKP precursors (Wen and Helmberger, 1998a). The morphology and aspect ratio (relief/half-width) of the structures are strongly dependent on the buoyancy number $B$ (or equivalently, the chemical density anomaly) and the relief (thickness) is proportional to the initial volume of ULVZ material. Complexities in the thermal 
and chemical structure can promote regional variation in ULVZ character.

Wicks et al. (2010) have recently demonstrated that addition of small amounts of iron-enriched $(\mathrm{Mg}, \mathrm{Fe}) \mathrm{O}$ mixed with silicates may explain the observed reductions in wavespeeds for ULVZs. We combine our geodynamic results with a Voigt-Reuss-Hill mixing model and compare with seismic data. For reasonable estimates of the CMB temperature and temperature drop, our synthesized model satisfies ULVZ wavespeed reductions and thicknesses inferred seismically, thus lending support to a solid-state origin for many ULVZs.

\section{Acknowledgements}

CitcomS was obtained from the Computational Infrastructure for Geodynamics (CIG). Discussions with Paul Asimow and Don Helmberger throughout this research proved most helpful, and the constructive comments of Paul Tackley and an anonymous reviewer further enhanced this paper. This work was supported by the NSF through grants EAR-0810303, EAR-0711542, and CSEDI EAR-0855815. Most figures were produced using GMT (Wessel and Smith, 1998). Contribution number 10046 of the Division of Geological and Planetary Sciences, California Institute of Technology.

\section{References}

Ammann, M. W., J. P. Brodholt, and D. P. Dobson (2009), DFT study of migration enthalpies in $\mathrm{MgSiO}_{3}$ perovskite, Phys. Chem. Miner., 36, 151-158, doi:10.1007/S0029-008-0265-Z.

Ammann, M. W., J. P. Brodholt, J. Wookey, and D. P. Dobson (2010), Firstprinciples constraints on diffusion in lower-mantle minerals and a weak $\mathrm{D}^{\prime \prime}$ layer, Nature, 465, 462-465, doi:10.1038/nature09052.

Andrault, D., M. Muñoz, N. Bolfan-Casanova, N. Guignot, J.-P. Perrillat, G. Aquilanti, and S. Pascarelli (2010), Experimental evidence for perovskite and post-perovskite coexistence throughout the whole $\mathrm{D}^{\prime \prime}$ region, Earth Planet. Sci. Lett., 293(1-2), 90-96, doi:10.1016/j.epsl.2010.02.026.

Auzende, A.-L., J. Badro, F. J. Reyerson, P. K. Weber, S. J. Fallon, A. Addad, J. Siebert, and G. Fiquet (2008), Element partitioning between magnesium silicate perovskite and ferropericlase: New insights into bulk 
lower-mantle geochemistry, Earth Planet. Sci. Lett., 269, 164-174, doi: 10.1016/j.epsl.2008.02.001.

Avants, M., T. Lay, and E. J. Garnero (2006), A new probe of ULVZ S-wave velocity structure: Array stacking of $\mathrm{ScS}$ waveforms, Geophys. Res. Lett., 33, L07314, doi:10.1029/2005GL024989.

Berryman, J. G. (2000), Seismic velocity decrement ratios for regions of partial melt in the lower mantle, Geophys. Res. Lett., 27(3), 421-424, doi:10.1029/1999GL008402.

Christensen, U. (1984), Instability of a hot boundary layer and initiation of thermo-chemical plumes, Ann. Geophys., 2(3), 311-320.

Cleary, J. R., and R. A. W. Haddon (1972), Seismic wave scattering near the core-mantle boundary: A new interpretation of precursors to PKP, Nature, 240, 549-551, doi:10.1038/240549a0.

Davies, G. F., and M. Gurnis (1986), Interaction of mantle dregs with convection: lateral heterogeneity at the core-mantle boundary, Geophys. Res. Lett., 13 (13), 1517-1520.

de Koker, N. (2010), Thermal conductivity of MgO periclase at high pressure: Implications for the D" region, Earth Planet. Sci. Lett., 292, 392-398, doi: 10.1016/j.epsl.2010.02.011.

Dobson, D. P., and J. P. Brodholt (2005), Subducted banded iron formations as a source of ultralow-velocity zones at the core-mantle boundary, Nature, 434, 371-374, doi:10.1038/nature03385.

Dubrovinsky, L. S., N. A. Dubrovinskaia, S. K. Saxena, H. Annersten, E. Hålenius, H. Harryson, F. Tutti, S. Rekhi, and T. Le Bihan (2000), Stability of ferropericlase in the lower mantle, Science, 289(5478), 430432, doi:10.1126/science.289.5478.430.

Garnero, E. J., and D. V. Helmberger (1995), A very slow basal layer underlying large-scale low-velocity anomalies in the lower mantle beneath the Pacific: evidence from core phases, Phys. Earth Planet. Inter., 91, 161-176, doi:10.1016/0031-9201(95)03039-Y. 
Garnero, E. J., and D. V. Helmberger (1996), Seismic detection of a thin laterally varying boundary layer at the base of the mantle beneath the centralPacific, Geophys. Res. Lett., 23(9), 977-980, doi:10.1029/95GL03603.

Garnero, E. J., and D. V. Helmberger (1998), Further structural constraints and uncertainties of a thin laterally varying ultralow-velocity layer at the base of the mantle, J. Geophys. Res., 103(B6), 12,495-12,509, doi: 10.1029/98JB00700.

Garnero, E. J., and A. K. McNamara (2008), Structure and dynamics of Earth's lower mantle, Science, 320, 626-628, doi:10.1126/science.1148028.

Garnero, E. J., and J. E. Vidale (1999), ScP; a probe of ultralow velocity zones at the base of the mantle, Geophys. Res. Lett., 26(3), 377-380, doi: 10.1029/1998GL900319.

Garnero, E. J., S. P. Grand, and D. V. Helmberger (1993), Low P-wave velocity at the base of the mantle, Geophys. Res. Lett., 20(17), 1843-1846, doi:10.1029/93GL02009.

Hansen, U., and D. A. Yuen (1988), Numerical simulations of thermalchemical instabilities at the core-mantle boundary, Nature, 334, 237-240, doi:10.1038/334237a0.

Havens, E., and J. Revenaugh (2001), A broadband seismic study of the lowermost mantle beneath Mexico: constraints on ultralow velocity zone elasticity and density, J. Geophys. Res., 106(B12), 30,809-30,820, doi: 10.1029/2000JB000072.

Helmberger, D., S. Ni, L. Wen, and J. Ritsema (2000), Seismic evidence for ultralow-velocity zones beneath Africa and the eastern Atlantic, $J$. Geophys. Res., 105(B10), 23,865-23,878, doi:10.1029/2000JB900143.

Helmberger, D. V., E. J. Garnero, and X. Ding (1996), Modeling twodimensional structure at the core-mantle boundary, J. Geophys. Res., 101 (B6), 13,963-13,972, doi:10.1029/96JB00534.

Helmberger, D. V., L. Wen, and X. Ding (1998), Seismic evidence that the source of the Iceland hotspot lies at the core-mantle boundary, Nature, 396, 251-255, doi:10.1038/24357. 
Hernlund, J. W., and A. M. Jellinek (2010), Dynamics and structure of a stirred partially molten ultralow-velocity zone, Earth Planet. Sci. Lett., 296(1-2), 1-8, doi:10.1016/j.epsl.2010.04.027.

Hernlund, J. W., and P. J. Tackley (2007), Some dynamical consequences of partial melting in Earth's deep mantle, Phys. Earth Planet. Inter., 162, 149-163, doi:10.1016/j.pepi.2007.04.005.

Hier-Majumder, S. (2008), Influence of contiguity on seismic velocities of partially molten aggregates, J. Geophys. Res., 113, B12205, doi: 10.1029/2008JB005662.

Hier-Majumder, S., and J. Revenaugh (2010), Relationship between the viscosity and topography of the ultralow-velocity zone near the coremantle boundary, Earth Planet. Sci. Lett., 299(3-4), 382-386, doi: 10.1016/j.epsl.2010.09.018.

Hofmeister, A. M. (2008), Inference of high thermal transport in the lower mantle from laser-flash experiments and the damped harmonic oscillator model, Phys. Earth Planet. Inter., 170, 201-206, doi: 10.1016/j.pepi.2008.06.034.

Hutko, A. R., T. Lay, and J. Revenaugh (2009), Localized double-array stacking analysis of PcP: $\mathrm{D}^{\prime \prime}$ and ULVZ structure beneath the Cocos Plate, Mexico, Central Pacific and North Pacific, Phys. Earth Planet. Inter., 173, 60-74, doi:10.1016/j.pepi.2008.11.003.

Idehara, K., A. Yamada, and D. Zhao (2007), Seismological constraints on the ultralow velocity zones in the lowermost mantle from core-reflected waves, Phys. Earth Planet. Inter., 165, 25-46, doi:10.1016/j.pepi.2007.07.005.

Irifune, T. (1994), Absence of an aluminous phase in the upper part of the Earth's lower mantle, Nature, 370, 131-133, doi:10.1038/370131a0.

Jackson, J. M., J. Zhang, J. Shu, S. V. Sinogeikin, and J. D. Bass (2005), High-pressure sound velocities and elasticity of aluminous $\mathrm{MgSiO}_{3}$ perovskite to $45 \mathrm{GPa}$ : Implications for lateral heterogeneity in Earth's lower mantle, Geophys. Res. Lett., 32, L21305, doi:10.1029/2005GL023522. 
Jellinek, A. M., and M. Manga (2002), The influence of a chemical boundary layer on the fixity, spacing and lifetime of mantle plumes, Nature, 418, 760-763, doi:10.1038/nature00979.

Karato, S., and B. B. Karki (2001), Origin of lateral variation of seismic wave velocities and density in the deep mantle, J. Geophys. Res., 106(B10), 21,771-21,783.

Kellogg, L. H., and S. D. King (1993), Effect of mantle plumes on the growth of $\mathrm{D}^{\prime \prime}$ by reaction between the core and mantle, Geophys. Res. Lett., 20(5), 379-382, doi:10.1029/93GL00045.

Kiefer, B., L. Stixrude, and R. M. Wentzcovitch (2002), Elasticity of $(\mathrm{Mg}, \mathrm{Fe}) \mathrm{SiO}_{3}-$ perovskite at high pressures, Geophys. Res. Lett., 29(11), 1539, doi:10.1029/2002GL014683.

Knittle, E., and R. Jeanloz (1991), Earth's core-mantle boundary: Results of experiments at high pressures and temperatures, Science, 251(5000), 1438-1443, doi:10.1126/science.251.5000.1438.

Kohler, M. D., J. E. Vidale, and P. M. Davis (1997), Complex scattering within $\mathrm{D}^{\prime \prime}$ observed on the very dense Los Angeles Region Seismic Experiment passive array, Geophys. Res. Lett., 24(15), 1855-1858, doi: 10.1029/97GL01823.

Kono, Y., T. Irifune, Y. Higo, T. Inoue, and A. Barnhoorn (2010), P$\mathrm{V}-\mathrm{T}$ relation of $\mathrm{MgO}$ derived by simultaneous elastic wave velocity and in situ x-ray measurements: A new pressure scale for the mantle transition region, Phys. Earth Planet. Inter., 183(1-2), 196-211, doi: 10.1016/j.pepi.2010.03.010.

Lay, T., J. Hernlund, E. J. Garnero, and M. S. Thorne (2006), A postperovskite lens and $\mathrm{D}^{\prime \prime}$ heat flux beneath the Central Pacific, Science, 314 (5803), 1272-1276, doi:10.1126/science.1133280.

Li, B., and J. Zhang (2005), Pressure and temperature dependence of elastic wave velocity of $\mathrm{MgSiO}_{3}$ perovskite and the composition of the lower mantle, Phys. Earth Planet. Inter., 151, 143-154, doi: 10.1016/j.pepi.2005.02.004. 
Lin, J.-F., D. L. Heinz, H.-K. Mao, R. J. Hemley, J. M. Devine, J. Li, and G. Shen (2003), Stability of magnesiowüstite in Earth's lower mantle, $P$. Natl. Acad. Sci. USA, 100 (8), 4405-4408, doi:10.1073/pnas.252782399.

Lin, S.-C., and P. E. van Keken (2006), Dynamics of thermochemical plumes: 1. plume formation and entrainment of a dense layer, Geochem. Geophy. Geosys., 7(2), Q02006, doi:10.1029/2005GC001071.

Loper, D. E., and I. A. Eltayeb (1986), On the stability of the D" layer, Geophys. Astro. Fluid, 36(3), 229-255, doi:10.1080/03091928608210086.

Luo, S.-N., S. Ni, and D. V. Helmberger (2001), Evidence for a sharp lateral variation of velocity at the core-mantle boundary from multipathed PKPab, Earth Planet. Sci. Lett., 189(3-4), 155-164, doi:10.1016.S00012821X(01)00364-8.

Manga, M., and R. Jeanloz (1996), Implications of a metal-bearing chemical boundary layer in D" for mantle dynamics, Geophys. Res. Lett., 23(22), 3091-3094, doi:10.1029/96GL03021.

Mao, W. L., H.-K. Mao, W. Sturhahn, J. Zhao, V. B. Prakapenka, Y. Meng, J. Shu, Y. Fei, and R. J. Hemley (2006), Iron-rich post-perovskite and the origin of ultralow-velocity zones, Science, 312, 564-565, doi: 10.1126/science.1123442.

Mao, W. L., et al. (2005), Iron-rich silicates in the Earth's D" layer, P. Natl. Acad. Sci. USA, 102(28), 9751-9753, doi:10.1073/pnas.0503737102.

McNamara, A. K., and S. Zhong (2004), Thermochemical structures within a spherical mantle: Superplumes or piles?, J. Geophys. Res., 109, B07402, doi:10.1029/2003JB002847.

McNamara, A. K., E. J. Garnero, and S. Rost (2010), Tracking deep mantle reservoirs with ultra-low velocity zones, Earth Planet. Sci. Lett., 299(1-2), 1-9, doi:10.1016/j.epsl.2010.07.042.

Mori, J., and D. V. Helmberger (1995), Localized boundary layer below the Mid-Pacific velocity anomaly identified from a PcP precursor, J. Geophys. Res., 100(B10), 20,359-20,365, doi:10.1029/95JB02243. 
Murakami, M., K. Hirose, N. Sata, and Y. Ohishi (2005), Post-perovskite phase transition and mineral chemistry in the pyrolitic lowermost mantle, Geophys. Res. Lett., 32, L03304, doi:10.1029/2004GL021956.

Ni, S., and D. V. Helmberger (2001a), Horizontal transition from fast to slow structures at the core-mantle boundary; South Atlantic, Earth Planet. Sci. Lett., 187(3-4), 301-310, doi:10.1016/S0012-821X(01)00273-4.

Ni, S., and D. V. Helmberger (2001b), Probing an ultra-low velocity zone at the core mantle boundary with $\mathrm{P}$ and $\mathrm{S}$ waves, Geophys. Res. Lett., 28(12), 2345-2348, doi:10.1029/2000GL012766.

Niu, F., and L. Wen (2001), Strong seismic scatterers near the core-mantle boundary west of Mexico, Geophys. Res. Lett., 28(18), 3557-3560, doi: 10.1029/2001GL013270.

Olson, P., G. Schubert, and C. Anderson (1987), Plume formation in the $\mathrm{D}^{\prime \prime}$ layer and the roughness of the core-mantle boundary, Nature, 327, 409-413.

Reasoner, C., and J. Revenaugh (2000), ScP constraints on ultralow-velocity zone density and gradient thickness beneath the Pacific, J. Geophys. Res., 105(B12), 28,173-28,182, doi:10.1029/2000JB900331.

Revenaugh, J., and R. Meyer (1997), Seismic evidence of partial melt within a possibly ubiquitous low-velocity layer at the base of the mantle, Science, 277(5326), 670-673, doi:10.1126/science.277.5326.670.

Richter, F. M., and D. P. McKenzie (1981), On some consequences and possible causes of layered mantle convection, J. Geophys. Res., 86(B7), 6133-6142, doi:10.1029/JB086iB07p06133.

Rondenay, S., and K. M. Fischer (2003), Constraints on localized core-mantle boundary structure from multichannel, broadband SKS coda analysis, $J$. Geophys. Res., 108(B11), 2537, doi:10.1029/2003JB002518.

Rost, S., and J. Revenaugh (2003), Small-scale ultralow-velocity zone structure imaged by ScP, J. Geophys. Res., 108(B1), 2056, doi: 10.1029/2001JB001627.

Rost, S., E. J. Garnero, Q. Williams, and M. Manga (2005), Seismological constraints on a possible plume root at the core-mantle boundary, Nature, 435, 666-669, doi:10.1038/nature03620. 
Rost, S., E. J. Garnero, and Q. Williams (2006), Fine-scale ultralow-velocity zone structure from high-frequency seismic array data, J. Geophys. Res., 111, doi:10.1029/2005JB004088.

Rost, S., E. J. Garnero, and W. Stefan (2010a), Thin and intermittent ultralow-velocity zones, J. Geophys. Res., 115, B06312, doi: 10.1029/2009JB006981.

Rost, S., E. J. Garnero, M. S. Thorne, and A. R. Hutko (2010b), On the absence of an ultralow-velocity zone in the North Pacific, J. Geophys. Res., 115, B04312, doi:10.1029/2009JB006420.

Sakai, T., et al. (2009), Fe-Mg partitioning between perovskite and ferropericlase in the lower mantle, Am. Mineral., 94, 921-925, doi: 10.2138/am.2009.3123.

Seagle, C. T., D. L. Heinz, A. J. Campbell, V. B. Prakapenka, and S. T. Wanless (2008), Melting and thermal expansion in the Fe-FeO system at high pressure, Earth Planet. Sci. Lett., 265(3-4), 655-665, doi: 10.1016/j.epsl.2007.11.004.

Simmons, N. A., and S. P. Grand (2002), Partial melting in the deepest mantle, Geophys. Res. Lett., 29(11), 1552, doi:10.1029/2001GL013716.

Sleep, N. H. (1988), Gradual entrainment of a chemical layer at the base of the mantle by overlying convection, Geophys. J. Int., 95, 437-447, doi: 10.1111/j.1365-246X.1988.tb06695.x.

Stackhouse, S., and J. P. Brodholt (2008), Elastic properties of the postperovskite phase of $\mathrm{Fe}_{2} \mathrm{O}_{3}$ and implications for ultra-low velocity zones, Phys. Earth Planet. Inter., 170, 260-266, doi:10.1016/j.pepi.2008.07.010.

Tackley, P. J. (1998), Three-dimensional simulations of mantle convection with a thermo-chemical basal boundary layer: $\mathrm{D}^{\prime \prime}$ ?, in The Core-Mantle Boundary Region, Geodyn. Ser., vol. 28, edited by M. Gurnis, M. Wysession, E. Knittle, and B. A. Buffett, pp. 231-254, AGU, Washington, D.C., doi:10.1029/GD028.

Tackley, P. J., and S. King (2003), Testing the tracer ratio method for modeling active compositional fields in mantle convection simulations, Geochem. Geophy. Geosys., 4(4), 8302, doi:10.1029/2001GC000214. 
Tan, E., M. Gurnis, and L. Han (2002), Slabs in the lower mantle and their modulation of plume formation, Geochem. Geophy. Geosys., 3(11), 1067, doi:10.1029/2001GC000238.

Tan, E., W. Leng, S. Zhong, and M. Gurnis (2007), Citcoms v3.0 - a compressible thermo-chemical mantle convection code, Eos Trans. AGU, 88(52), Fall Meet. Suppl., Abstract DI14A-01.

Tateno, S., K. Hirose, N. Sata, and Y. Ohishi (2007), Solubility of FeO in $(\mathrm{Mg}, \mathrm{Fe}) \mathrm{SiO}_{3}$ perovskite and the post-perovskite phase transition, Phys. Earth Planet. Inter., 160(3-4), 319-325, doi:10.1016/j.pepi.2006.11.010.

Thompson, P. F., and P. J. Tackley (1998), Generation of megaplumes from the core-mantle boundary in a compressible mantle with temperature-dependent viscosity, Geophys. Res. Lett., 25(11), 1999-2002, doi:10.1029/98GL01228.

Thorne, M. S., and E. J. Garnero (2004), Inferences on ultralow-velocity zone structure from a global analysis of SPdKS waves, J. Geophys. Res., 109, B08301, doi:10.1029/2004JB003010.

Vidale, J. E., and M. A. H. Hedlin (1998), Evidence for partial melt at the core-mantle boundary north of Tonga from the strong scattering of seismic waves, Nature, 391, 682-685, doi:10.1038/35601.

Watt, J. P., G. F. Davies, and R. J. O'Connell (1976), The elastic properties of composite materials, Rev. Geophys., 14(4), 541-563, doi: 10.1029/RG014I004P00541.

Wen, L. (2001), Seismic evidence for a rapidly varying compositional anomaly at the base of the Earth's mantle beneath the Indian Ocean, Earth Planet. Sci. Lett., 194(1-2), 83-95, doi:10.1016/S0012-821X(01)00550-7.

Wen, L., and D. V. Helmberger (1998a), Ultra-low velocity zones near the core-mantle boundary from broadband PKP precursors, Science, 279, 1701-1703, doi:10.1126/science.279.5357.1701.

Wen, L., and D. V. Helmberger (1998b), A two-dimensional P-SV hybrid method and its application to modeling localized structures near the core-mantle boundary, J. Geophys. Res., 103(B8), 17,901-17,918, doi: 10.1029/98JB01276. 
Wessel, P., and W. H. F. Smith (1998), New, improved version of Generic Mapping Tools released, Eos Trans. AGU, 79(47), 579.

Wicks, J. K., J. M. Jackson, and W. Sturhahn (2010), Very low sound velocities in iron-rich $(\mathrm{Mg}, \mathrm{Fe}) \mathrm{O}$ : Implications for the core-mantle boundary region, Geophys. Res. Lett., 3\%, L15304, doi:10.1029/2010GL043689.

Williams, Q., and E. J. Garnero (1996), Seismic evidence for partial melt at the base of Earth's mantle, Science, 273, 1528-1530, doi: 10.1126/science.273.5281.1528.

Williams, Q., J. Revenaugh, and E. Garnero (1998), A correlation between ultra-low basal velocities in the mantle and hot spots, Science, 281, 546549, doi:10.1126/science.281.5376.546.

Yamazaki, D., and S. Karato (2001), Some mineral physics constraints on the rheology and geothermal structure of Earth's lower mantle, Am. Mineral., 86(4), 385-391.

Youngs, B. A. R., and G. A. Houseman (2009), Formation of steep-sided topography from compositionally distinct dense material at the base of the mantle, J. Geophys. Res., 114, B04404, doi:10.1029/2007JB005487.

Yuen, D. A., and W. R. Peltier (1980), Mantle plumes and the thermal stability of the $\mathrm{D}^{\prime \prime}$ layer, Geophys. Res. Lett., 7(9), 625-628, doi: 10.1029/GL007I009P00625.

Zhang, Y., J. Ritsema, and M. Thorne (2009), Modeling the ratios of SKKS and SKS amplitudes with ultra-low velocity zones at the core-mantle boundary, Geophys. Res. Lett., 36, L19303, doi:10.1029/2009GL040030.

Zhong, S., M. Zuber, L. N. Moresi, and M. Gurnis (2000), Role of temperature-dependent viscosity and surface plates in spherical shell models of mantle convection, J. Geophys. Res., 105(B5), 11,063-11,082, doi: 10.1029/2000JB900003. 
Table 1: Model parameters

\begin{tabular}{|c|c|c|c|}
\hline Parameter & Symbol & Value & Units \\
\hline Density & $\rho$ & 5500 & $\mathrm{~kg} \mathrm{~m}^{-3}$ \\
Thermal expansion coefficient & $\alpha$ & $10^{-5}$ & $\mathrm{~K}^{-1}$ \\
Temperature drop & $\Delta T$ & 1500 & $\mathrm{~K}$ \\
Mantle depth & $D$ & 2890 & $\mathrm{~km}$ \\
Gravity & $g$ & 10.3 & $\mathrm{~m} \mathrm{~s}^{-2}$ \\
Thermal diffusivity & $\kappa$ & $10^{-6}$ & $\mathrm{~m}^{2} \mathrm{~s}^{-1}$ \\
Reference viscosity & $\eta_{0}$ & $10^{22}$ & $\mathrm{~Pa} \mathrm{~s}$ \\
Viscosity exponent & $q$ & 3 & - \\
Thermal Rayleigh number & $R a$ & $2 \times 10^{6}$ & - \\
Thermal boundary layer initial thickness & $d_{t}$ & 66 & $\mathrm{~km}^{-6}$ \\
Buoyancy number & $B$ & $0.5,0.75,1,1.25,2,4,6$ & - \\
Chemical density & $\Delta \rho_{c h}$ & $B \rho \alpha \Delta T$ & $\mathrm{~kg} \mathrm{~m}^{-3}$ \\
Chemical Rayleigh number & $R b$ & $B R a$ & - \\
Chemical layer initial thickness & $d_{c h}$ & $2,4,8,16,24,32$ & $\mathrm{~km}$ \\
\hline
\end{tabular}




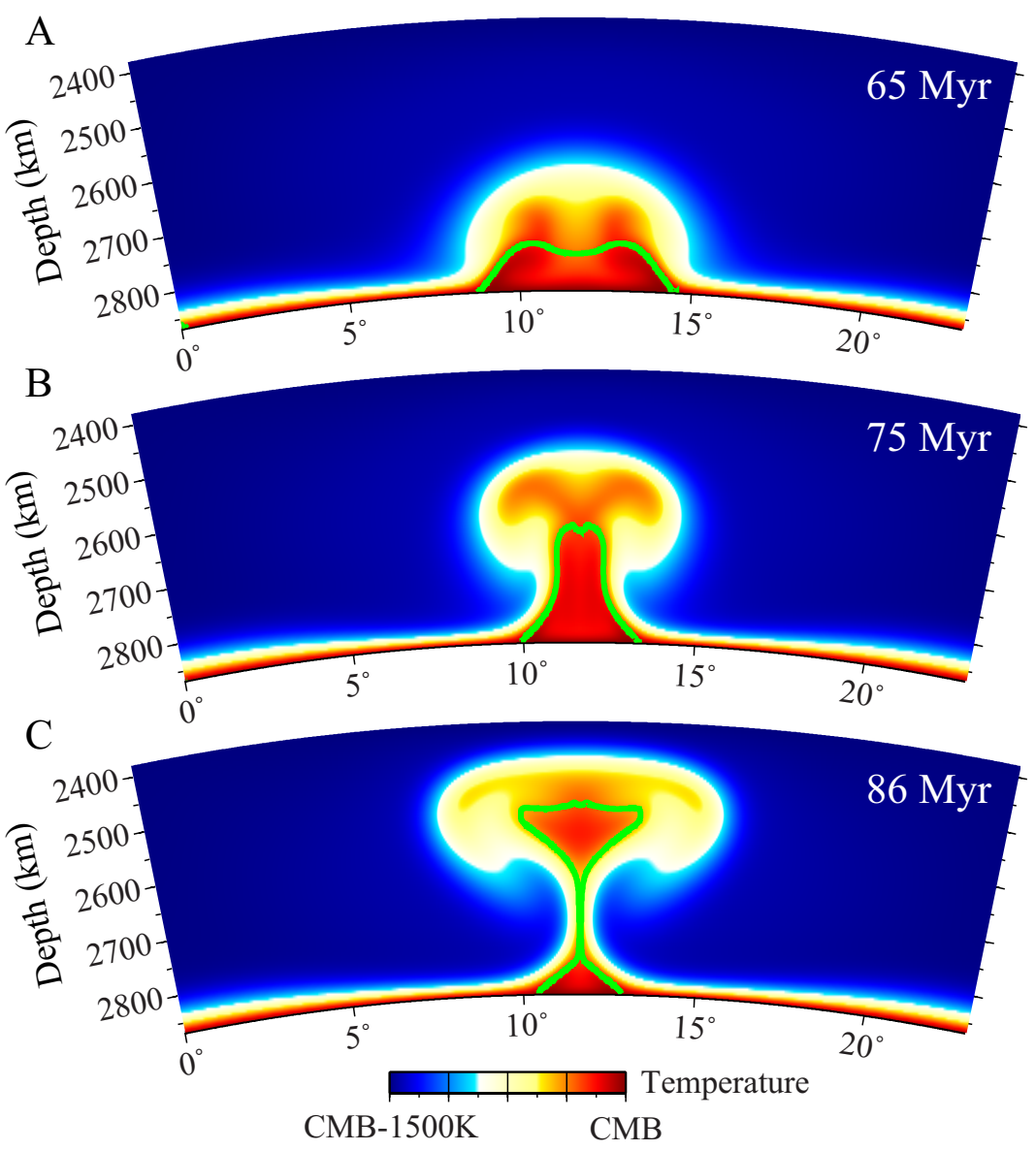

Figure 1: Representative behavior during the transient period for a model with a low chemical density anomaly and hence entrainment $\left(B=0.5, d_{c h}=16 \mathrm{~km}\right.$, impermeable domain). The ULVZ component is contained within the area outlined in green and the CMB. 


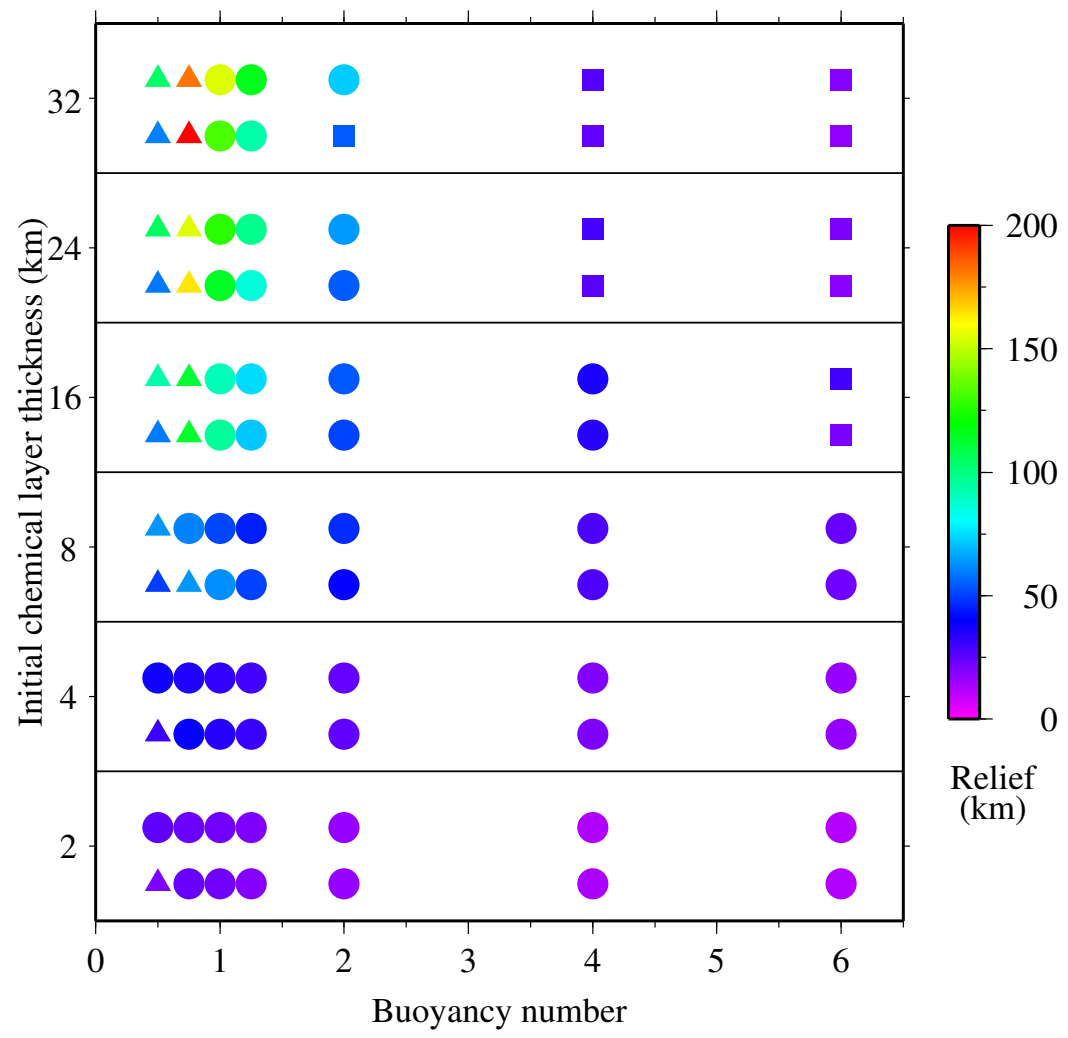

$\Delta$ Entrainment No entrainment Ubiquitous layer

Figure 2: Relief of the structures at steady-state. For each initial chemical layer thickness, datapoints corresponding to the impermeable cases are located above the points for the permeable cases. 'Ubiquitous layer' refers to cases where the chemical layer occupies the full lateral extent of the domain. 


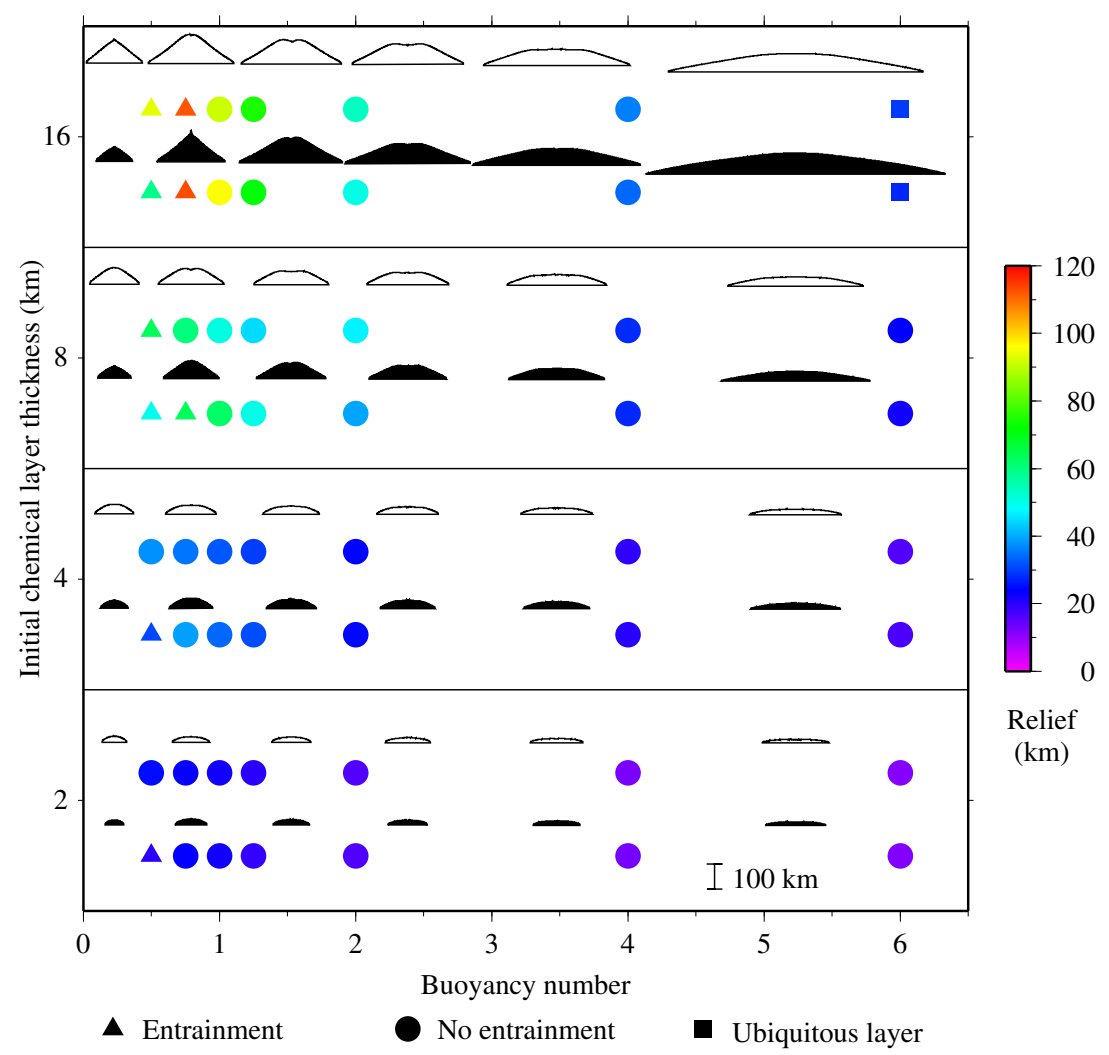

Figure 3: Relief of the structures at steady-state. The morphologies for $B=0.5$ to $B=4$, plotted to scale, are shown in successive order from left to right above their corresponding datapoints. For $B=6$ the morphologies are omitted because of space consideration but are comparable to $B=4$. Permeable cases: black outline, impermeable cases: black fill. Note color scale is different in Fig. 2. 


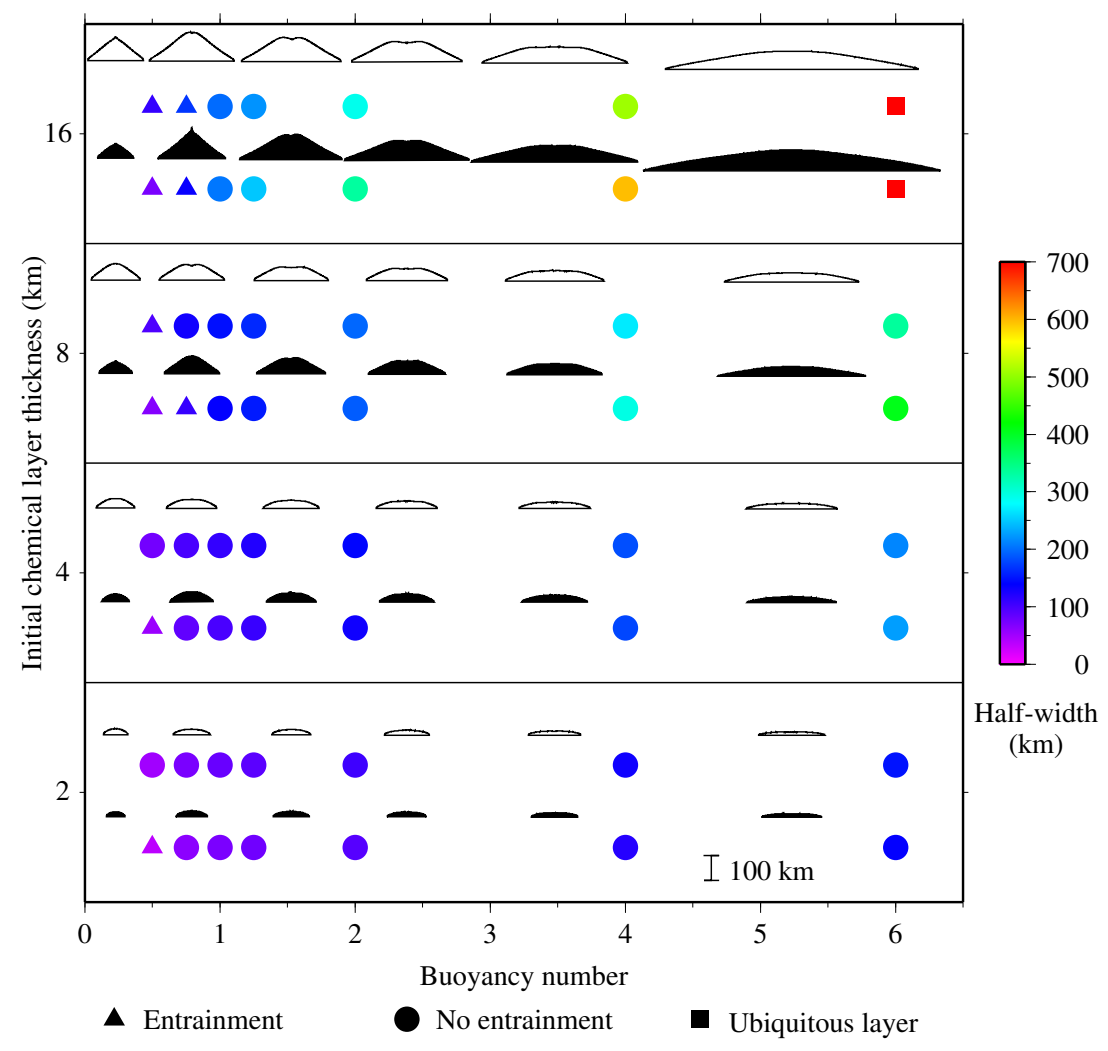

Figure 4: Half-width of the structures at steady-state. See Fig. 3 caption for legend. 


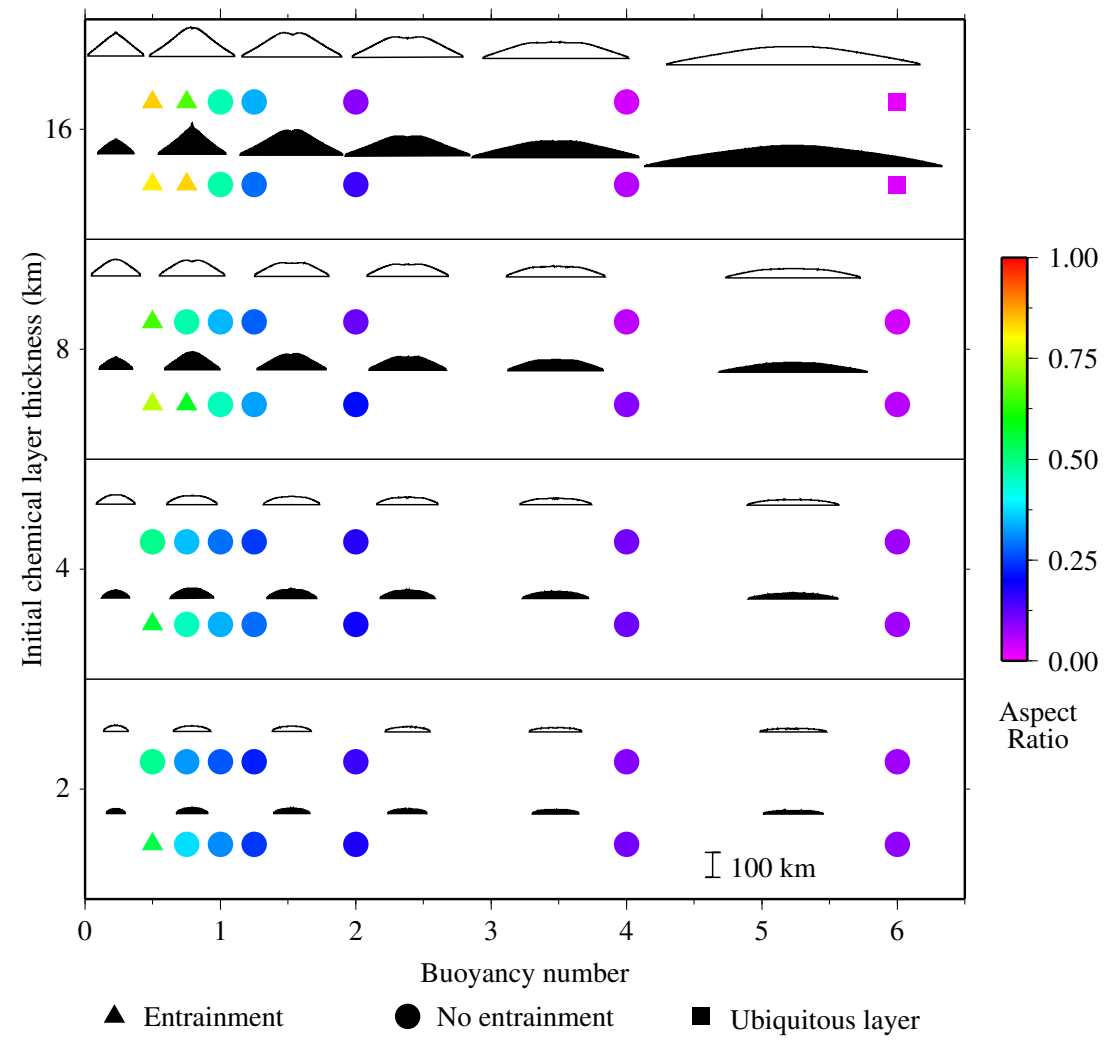

Figure 5: Aspect ratio (relief/half-width) of the structures at steady-state. See Fig. 3 caption for legend. 

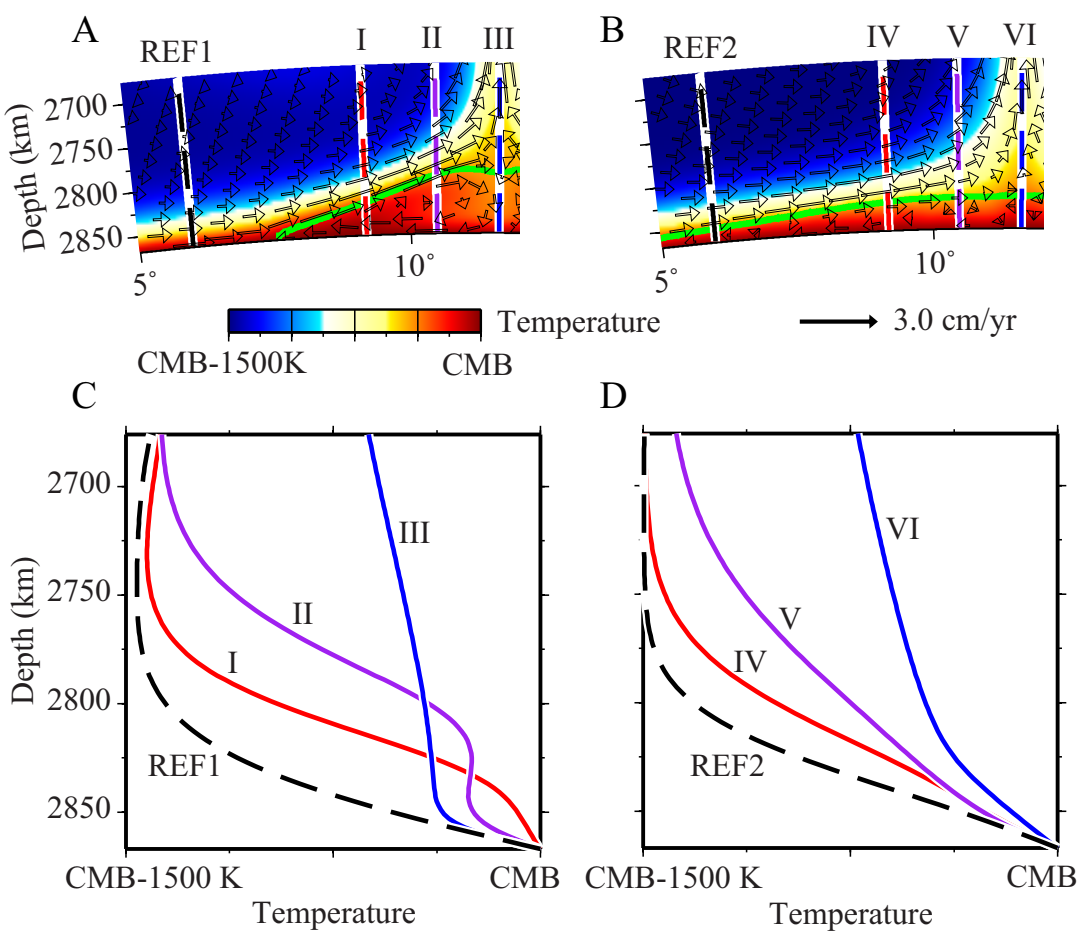

Figure 6: Steady-state behavior of a thin $(\mathrm{Mg}, \mathrm{Fe}) \mathrm{O}$-containing layer. (A) Countercirculation driven by viscous coupling ( $B=1.25, d_{c h}=16 \mathrm{~km}$, impermeable domain). The ULVZ component is contained within the area outlined in green and the CMB. (C) Temperature profiles: reference REF1, upwelling I, center II, and downwelling III. (B) Sluggish convection ( $B=4, d_{c h}=16 \mathrm{~km}$, permeable domain). (D) Temperature profiles (REF2, IV, V, VI) are at the same locations as in (C). 

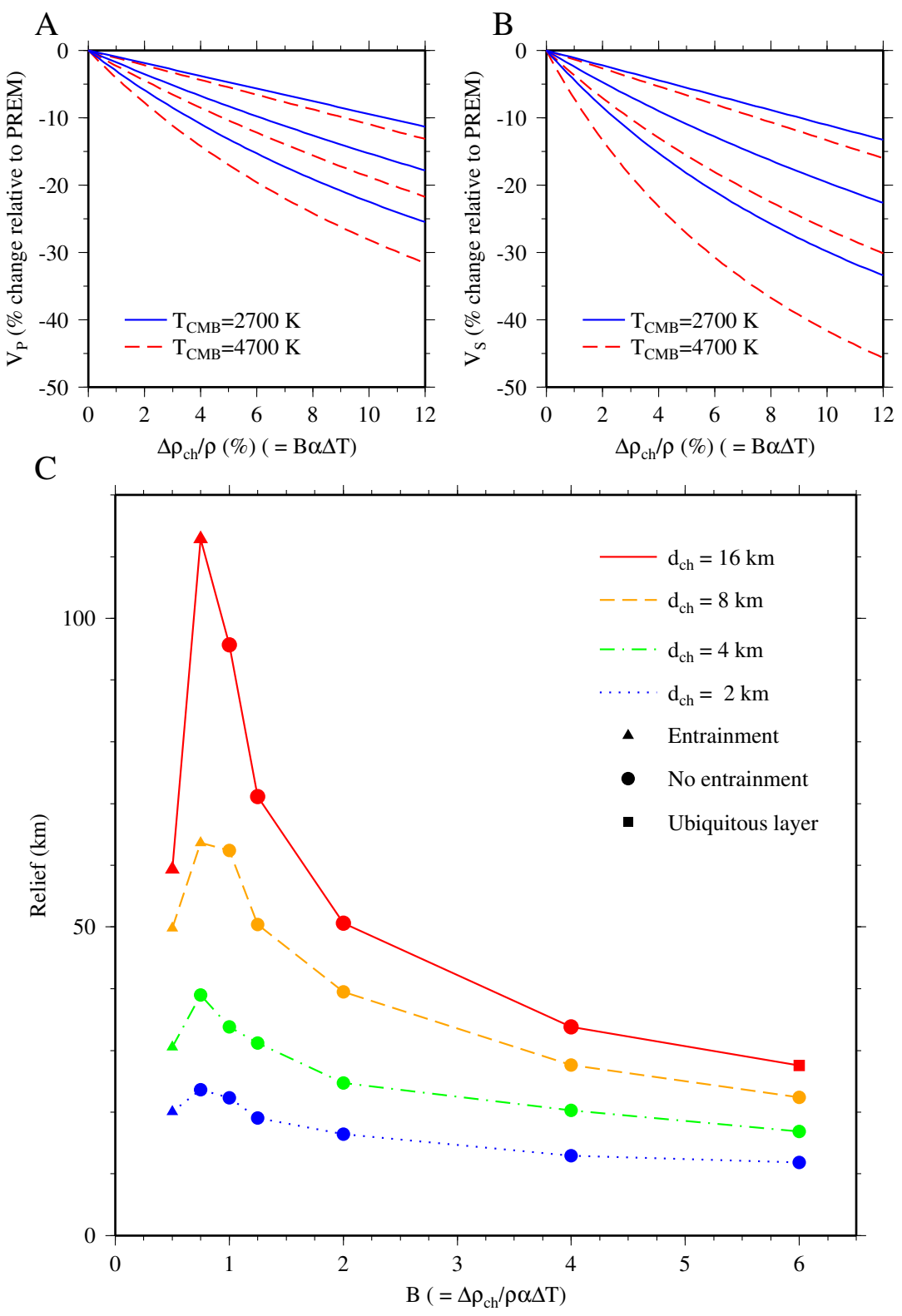

Figure 7: (A and B). Voigt-Reuss-Hill (VRH) wavespeed determinations at two endmember CMB temperature estimates for the "PREM + Mw" mixing model. Voigt (upper), Reuss (lower), Hill (arithmetic average). See text for model details. (C) Relief of structures for the impermeable cases. 

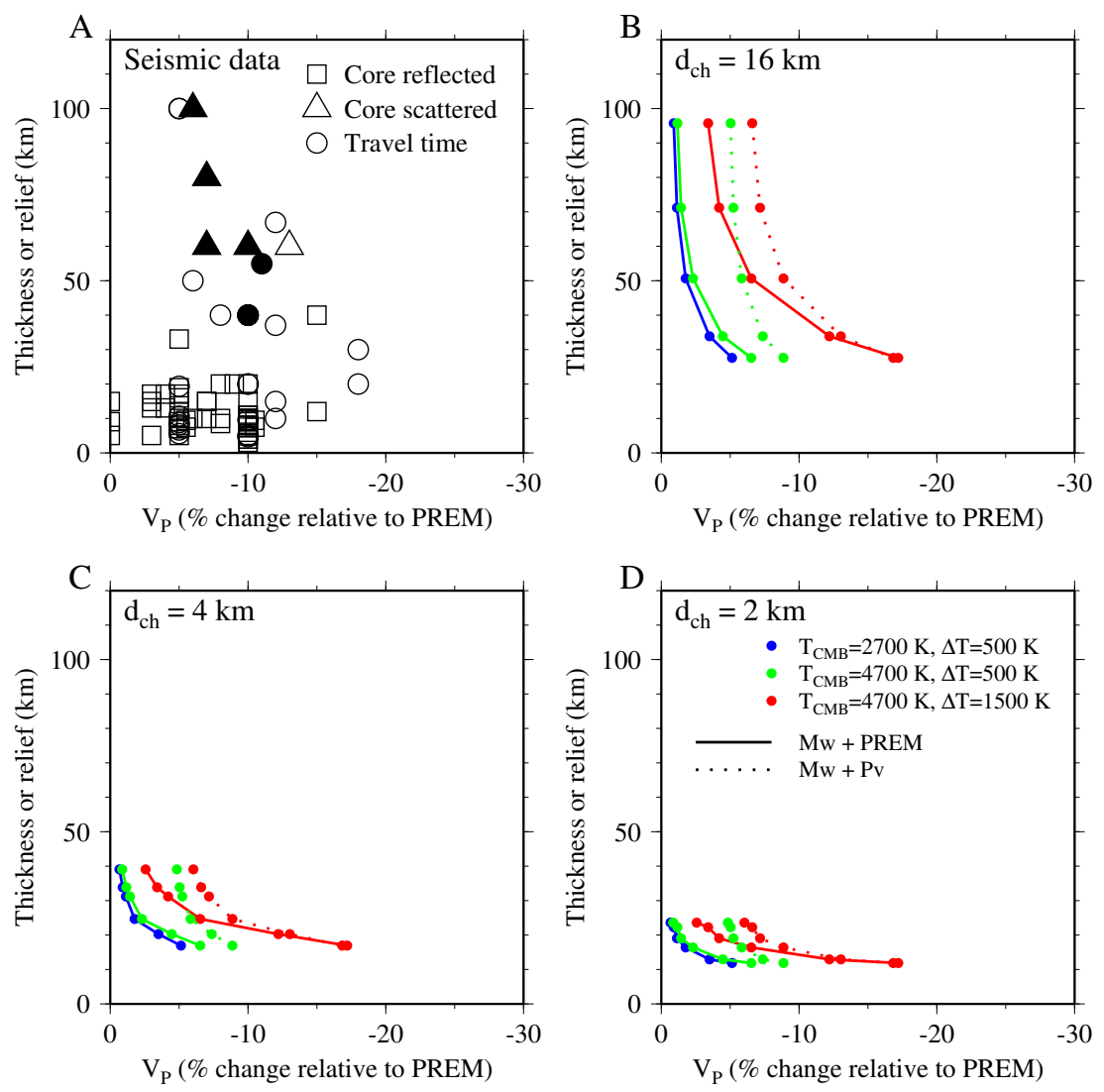

Figure 8: (A) Summary of seismically inferred ULVZ thicknesses and P-wave velocity reductions found globally. Following the nomenclature of Thorne and Garnero (2004): $\square$ Precursors to core reflected phases (Mori and Helmberger, 1995; Kohler et al., 1997; Garnero and Vidale, 1999; Reasoner and Revenaugh, 2000; Havens and Revenaugh, 2001; Rost and Revenaugh, 2003; Rost et al., 2005, 2006; Hutko et al., 2009; Rost et al., 2010a), $\triangle$ scattered core phases (Vidale and Hedlin, 1998; Wen and Helmberger, 1998a; Ni and Helmberger, 2001b; Niu and Wen, 2001), $\bigcirc$ travel time and waveform anomalies (Garnero et al., 1993; Garnero and Helmberger, 1995, 1996; Helmberger et al., 1996, 1998; Wen and Helmberger, 1998b; Helmberger et al., 2000; Simmons and Grand, 2002; Luo et al., 2001; Ni and Helmberger, 2001a; Wen, 2001; Rondenay and Fischer, 2003; Thorne and Garnero, 2004). Filled symbols denote 2-D studies. (B, C, and D) Models using the Hill bound, for various $\mathrm{d}_{c h}$, temperature at the $\mathrm{CMB}\left(\mathrm{T}_{C M B}\right)$, and temperature drop $(\Delta \mathrm{T})$. Solid lines are the "Mw + PREM" model and dotted lines are the "Mw + Pv" model. 

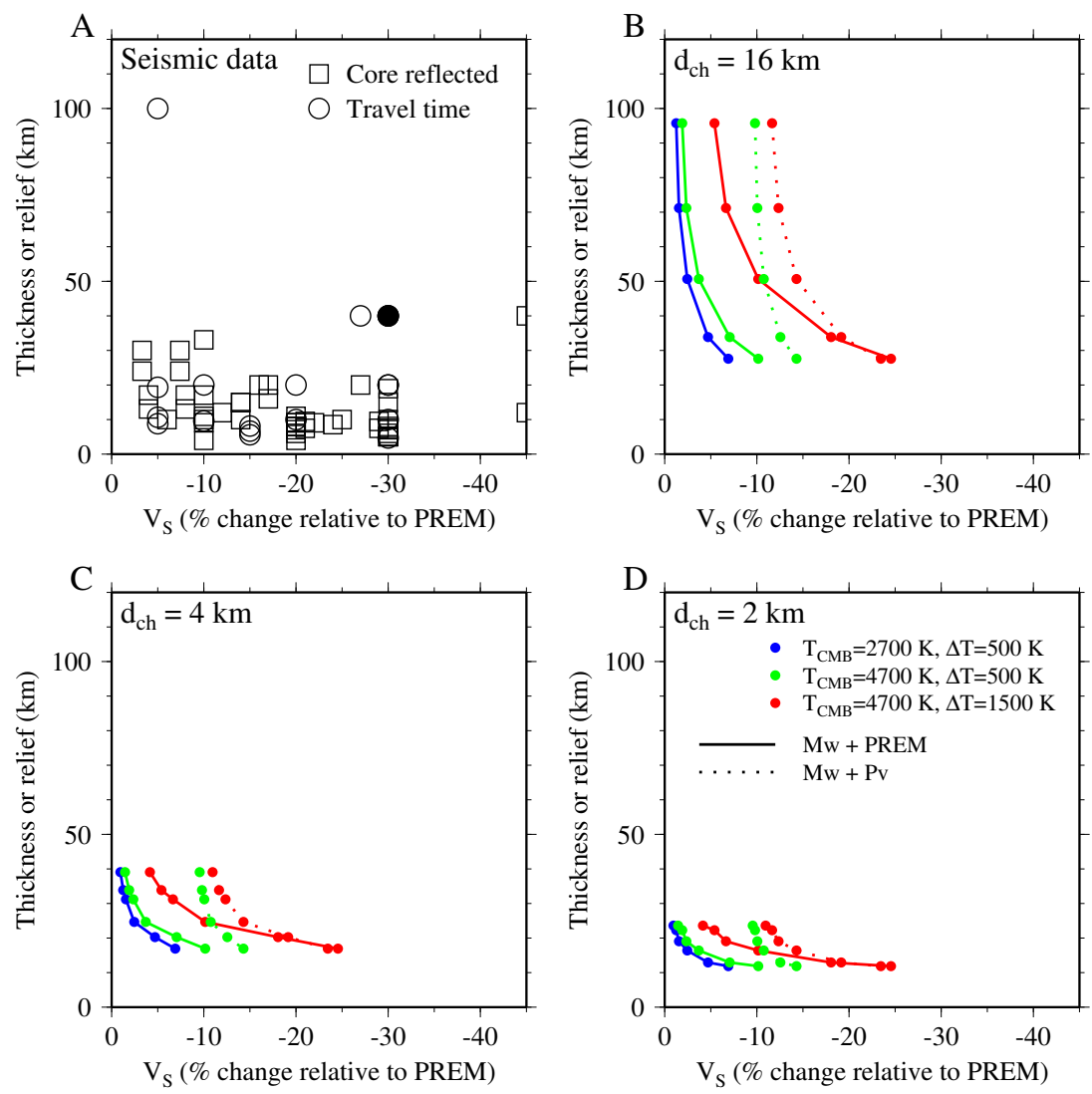

Figure 9: (A) Seismically inferred ULVZ thicknesses and S-wave velocity reductions found globally. Following the nomenclature of Thorne and Garnero (2004): $\square$ Precursors to core reflected phases (Kohler et al., 1997; Garnero and Vidale, 1999; Reasoner and Revenaugh, 2000; Havens and Revenaugh, 2001; Rost and Revenaugh, 2003; Rost et al., 2005, 2006; Avants et al., 2006; Hutko et al., 2009; Rost et al., 2010a), $\bigcirc$ travel time and waveform anomalies (Garnero and Helmberger, 1995; Helmberger et al., 1998; Wen and Helmberger, 1998b; Helmberger et al., 2000; Simmons and Grand, 2002; Ni and Helmberger, 2001a; Rondenay and Fischer, 2003; Thorne and Garnero, 2004; Zhang et al., 2009). Filled symbols denote 2-D studies. (B, C, and D) Models using the Hill bound, for various $\mathrm{d}_{c h}$, temperature at the $\mathrm{CMB}\left(\mathrm{T}_{C M B}\right)$, and temperature drop $(\Delta \mathrm{T})$. Solid lines are the "Mw + PREM" model and dotted lines are the "Mw + Pv" model. 